account of the sytemic use of idoxuridine in the treatment of a severe D.N.A.-virus infection, herpes simplex encephalitis.

The place of idoxuridine in the chemotherapy of viral encephalitis, with or without corticosteroids, must await further trial; at least the facts of this case suggest that it may have antiviral action within the central nervous system.

As the chemotherapy of virus disease advances drugs are likely to be developed which are type-specific. Early identification of virus will be important. Brain biopsy, with the technique of Blackwood and Cumings (1959), is a safe and reliable procedure, but successful isolation of virus may depend on the speed with which material reaches the laboratory.

ADDENDUM.-Since this report was submitted for publication Breeden et al. (1966) have described a case of herpes simplex encephalitis in a middle-aged man who recovered after treatment by cerebral decompression and a seven-day course of idoxuridine.
Our thanks are due to Professor W. Blackwood for the histological report ; to Professor J. N. Cumings for the chemical report; to Dr. J. A. Dudgeon and Dr. N. J. Legg for the virus studies on the material obtained by brain biopsy ; and to Dr. D. G. Fleck for the serological tests for toxoplasmosis.

\section{REFERENCES}

Blackwood, W., and Cumings, J. N. (1959). Lancet, 2, 23.

Breeden, C. J., Hall, T. C., and Tyler, H. R. (1966). Ann. intern. Med., 65, 1050 .

Brit. med. F., 1966, 1, 1497.

Calabresi, P.'(1965). Ann. N.Y. Acad. Sci., 130, 192.

Cardoso, S. S., Finch, S. C., Kligerman, M. M., von Essen, C. F., Chu, M. Y., and Welch, A. D. (1961). Cancer Res., 21, 550 . Herrmann, E. C., jun. (1961). Proc. Soc. exp. Biol. (N.Y.), 107, 142. Herrmann, E. C., Jungliks, J., Engle, C., and Perlman, P. L. (1960). Ibid., 103, 625. Kaplan, A. S., Ben-Porat, T., and Kamiya, T. (1965). Ann. N.Y. Acad. Sci., 130, 226.

Kaufman, H. E. (1962). Proc. Soc. exp. Biol. (N.Y.), 109, 251.

Martola, E. L., and Dohlman, C. (1962). Arch. Ophthal., 68, 235. Leopold, I. H. (1965). Ann. N.Y. Acad. Sci., 130, 181.

Prusoff, W. H., Bakhle, Y. S., and Sekely, L. (1965). Ibid., 130, 135.

\title{
Evaluation of Autogenous Vein Bypass Grafts for Femoro-popliteal Arterial Occlusion
}

\author{
R. M. BADDELEY,* M.B., CH.B., B.SC., F.R.C.S. ; L. J. LAWSON,* M.B., CH.B., B.SC., F.R.C.S. \\ F. ASHTON,* CH.M., F.R.C.s. ; G. SLANEY,* CH.M., F.R.C.S.
}

Our experience and dissatisfaction with arterial homografts and synthetic bypass prostheses for femoro-popliteal occlusive arterial disease have already been published (Ashton et al., 1962); they concurred with the opinions of other surgeons in this field (Edwards, 1960 ; Taylor, 1962 ; Cockett and Maurice, 1963 ; Irvine et al., 1963 ; Szilagyi et al., 1964). As a result these techniques were abandoned and replaced by autogenous vein bypass grafts or vein patch thromboendarterectomy. This paper reports the results of 87 femoro-popliteal autogenous vein bypass grafts performed in the subsequent four-year period.

\section{Case Material}

These 87 femoro-popliteal bypass grafts with reversed autogenous saphenous vein were carried out between January 1962 and July 1965. The progress of these cases up to 31 January 1966 has been reviewed in all but six deceased patients. With the exception of two cases of traumatic arterial injury the operations were performed for atherosclerotic arterial occlusive disease.

All patients had intermittent claudication severe enough to halt them after walking 150 yards (135 metres) or less along a flat hospital corridor at their " normal" pace ; in most cases the stopping distance was less than 100 yards (90 metres). This empirical test was carried out immediately after the subjects' arrival in hospital to avoid the benefit a period of bed rest might have had on exercise tolerance. In all patients popliteal and pedal pulses were absent and in 43 limbs there was rest pain with trophic changes in the foot.

Arteriography by the Seldinger or translumbar technique was carried out in each case. Additional arteriography by direct

* Department of Surgery, Queen Elizabeth Hospital, Birmingham 15, and the University of Birmingham Medical School. injection into the femoral artery was occasionally employed to assess the details of the popliteal run-off.

At the follow-up examination grafts were denoted as successful and patent if pulsation was present in the graft itself or if pedal pulses were present. This was usually accompanied by relief of intermittent claudication and other evidence of ischaemia, though in two patients with still patent grafts this was not so; they presumably had distal small-vessel disease. Failed grafts showed loss of graft and pedal pulses and, in many but not all, recurrence of symptoms.

\section{Surgical Technique}

This is similar to that of Kunlin (1951). The ipsilateral long saphenous vein is dissected free from the subcutaneous fat through two incisions placed over it in the upper and lower thirds of the thigh; undercutting of the skin flaps must be avoided and particular care taken not to constrict the vein when its tributaries are ligated with fine silk. After removal the vein is irrigated and distended with a solution of normal saline containing $0.1 \%$ procaine and heparin in 50 units $/ \mathrm{ml}$.

The reversed saphenous vein is anastomosed to the popliteal artery end-to-side, but this anastomosis is left incomplete to permit subsequent flush-out manœuvres. Taking great care to avoid twisting, the vein is then passed subcutaneously to the groin, where the erstwhile distal end is anastomosed to the common femoral artery end-to-side. Before completion of the upper anastomosis "back-bleeding" from the profunda artery and flushing down the common femoral artery are carried out. This anastomosis is completed, and temporary blood flow down the graft is then used to flush out any clot, after which it is reclamped at its upper end and emptied digitally. The distal run-off is "back-bled," reclamped, and this anastomosis is then completed; the clamps are removed and blood flow down the 
leg is restored. If after a period of 20 minutes the graft is still pulsating satisfactorily the wounds are closed.

Patients usually remain in bed for three to five days, and phenindione therapy is begun after 48 hours unless contraindicated. Antibiotics (cloxacillin and streptomycin) are begun the day before operation and continued for five days afterwards.

\section{Results}

The 87 grafts were placed in 79 patients, 10 of whom were female. The age distribution confirmed the usual peak incidence during the period 50-69 years.

Outcome of Grafts.- The period of follow-up ranges from 6 to 59 months, as illustrated in Fig. 1, which shows the distribution of grafts still patent: there were 55 successful grafts in 49 living patients. Five additional patients have died, but their grafts were patent at the time of death (Fig. 1). Twenty-seven grafts in 25 patients occluded. Six " hospital" failures followed within 28 days of operation; thereafter graft occlusions occurred over the next 24 months (Fig. 2).

Prognosis of Patency of Vein Grafts.-Of the 87 bypass grafts performed $81(93 \%)$ were patent at the time of the patient's discharge from hospital. After six months 7 of the
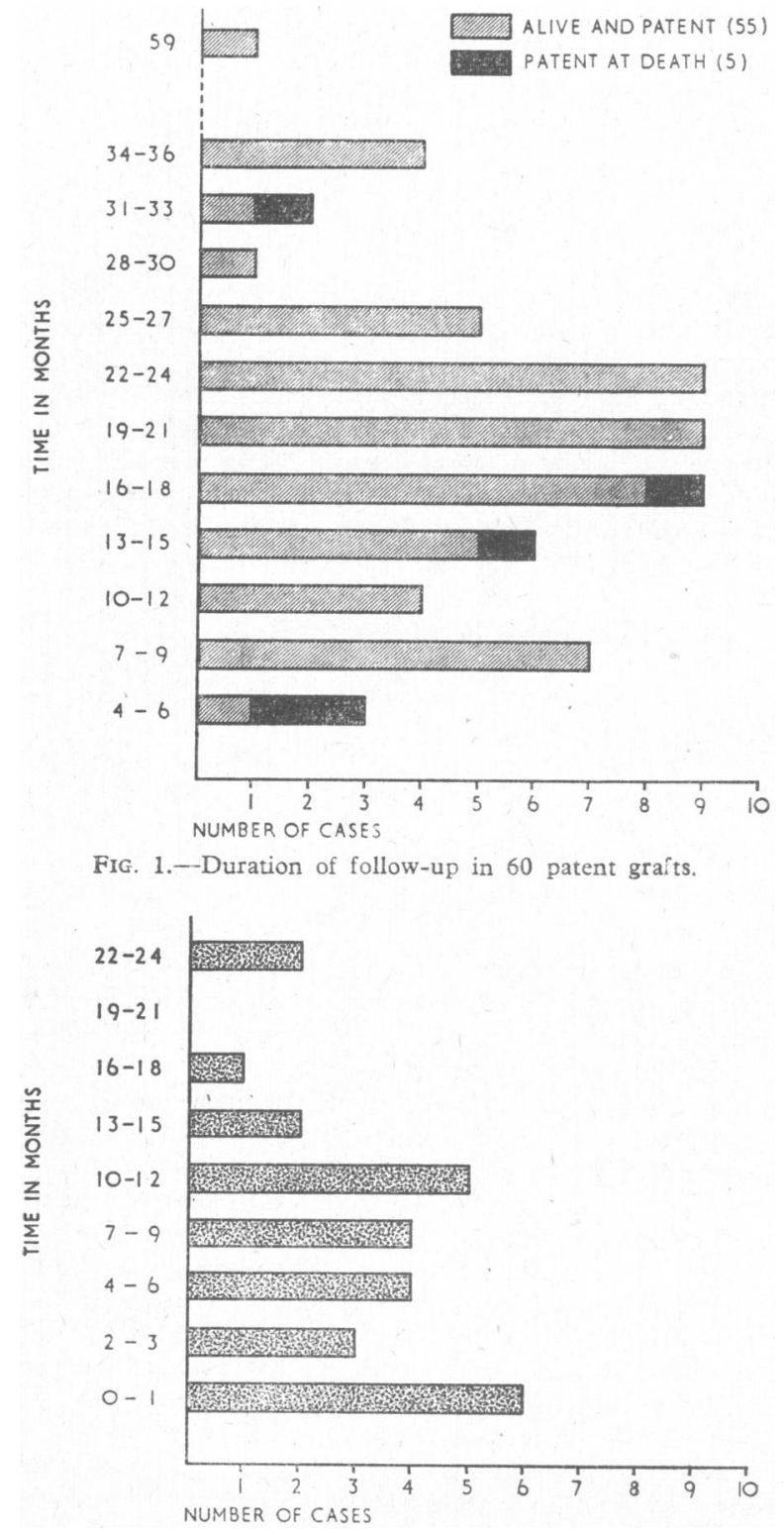

FIG. 2.-Duration of patency in 27 occluded grafts
81 initially successful grafts had thrombosed, and two patients had died with their grafts patent. Thus of the 79 surviving grafts $72(91 \%)$ remained patent for six months. If the grafts performed less than one year before review are excluded the patency rate at 12 months can be determined. Thus of 62 grafts available for review three had to be eliminated owing to failure while in hospital, together with five because of death. There were 16 late failures. The late patency rate at one year was therefore $73 \%$. Similarly, with the minimal follow-up period at two years, 21 grafts are available for study. No graft occlusions occurred in the initial hospital period, but three had to be excluded owing to death. There were six late failures ; thus the long-term patency rate at two years was $67 \%$. The above figures are summarized and compared with other series in Table I.

TABLE I.-Comparison of Various Series of Femoro-popliteal Arterial

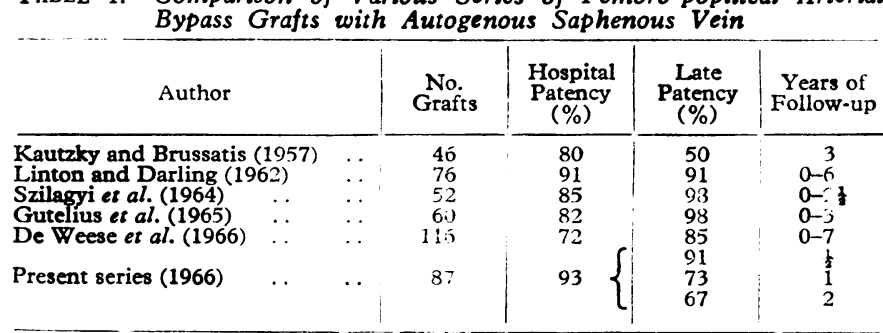

Salvage of Limbs.-Limbs with rest pain, ischaemic ulceration, or even frank gangrene were in imminent risk of amputation; 43 of our 79 patients were in this category. Two additional patients suffering from severe arterial injury to the thigh due to shotgun wounds were also in danger of amputation. The results of femoro-popliteal vein grafts in these 45 patients showed that 22 were still patent and functioning satisfactorily, their symptoms being completely eliminated and normal healing achieved. Twenty grafts had thrombosed, and 12 of these limbs had undergone Gritti-Stokes amputation. However, the remaining eight still remained intact, and even though evidence of slight vascular insufficiency persisted their rest pain and ulceration remained cured. The remaining three patients died at 5, 26, and 32 months, respectively, after their graft, which in each case was still patent at the time of death. Including these three cases the limb salvage rate was $33(73 \%)$ out of 45 legs (Table II). This means that three out of every

TABLB II.-Limb Salvage

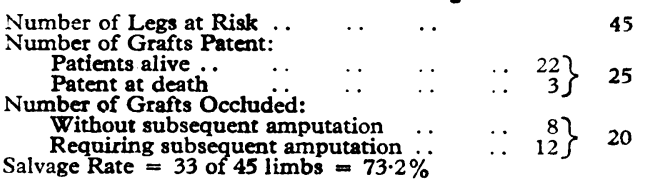

four limbs which would otherwise have been amputated were saved. Experience has convinced us that, in some patients at least, where a graft is successfully performed in a limb which would otherwise have been amputated subsequent failure of the graft may still leave a functionally useful limb. This "tiding over" concept is, we think, valuable and merits wider recognition.

Influence of Distal Site of Graft Insertion on Patency.-The distal insertion of vein grafts into the popliteal artery was noted in 84 operations, records being deficient in three cases. The outcome of grafts in which the distal insertion was below or at the level of the knee joint is shown in Table III. This confirms

\begin{tabular}{|c|c|c|c|}
\hline Level of Graft Insertion & No. of Cases & No. Patent & No. Oscluded \\
\hline $\begin{array}{l}\text { Above knee-joint level .. } \\
\text { Below knee-joint level } . . \\
\text { At knee-joint level }\end{array}$ & $\begin{array}{c}42^{*} \\
31 \dagger \\
6\end{array}$ & $\begin{array}{l}33(78 \cdot 6 \%) \\
15(48 \cdot 4 \%) \\
4\end{array}$ & $\begin{array}{l}9(21.4 \%) \\
16(51 \cdot 6 \%)\end{array}$ \\
\hline
\end{tabular}

* Excluding one deceased patient. + Excluding four deceased patients. 
that the results of below-knee insertions are much worse than those above the knee.

Influence of Postoperative Anticoagulant Therapy on Graft Patency.-Phenindione therapy was continued postoperatively without interruption in 42 patients. In the remainder it was either contraindicated because of peptic ulcer or discontinued because of epistaxis, haematuria, haematoma, or sensitivity rash. A few patients failed to take the tablets. Of the 55 patients with patent grafts 31 were on anticoagulant therapy, and of the 27 with occluded grafts 11 were on anticoagulants. Thus anticoagulants did not seem to influence graft patency or late failure.

Influence of Postoperative Anticoagulant Therapy on Incidence of Amputation.-The routine type of major amputation performed on this vascular unit is the Gritti-Stokes procedure, and this was carried out in 11 of the 27 failed grafts. Of these 11 two had been treated with phenindione up to the time of amputation but nine had not. Among the 16 occluded grafts which did not require amputation nine were anticoagulated and seven were not. This apparently beneficial effect of anticoagulation was noted in our previous study, but, unfortunately, the numbers involved were too small for statistical evaluation (Ashton et al., 1962).

Effect of Sympathectomy.-Lumbar sympathectomy was performed in 26 limbs, an inadequate figure from which to draw significant conclusions. However, 10 grafts were still patent but 16 had failed. In three of the failures the operation was performed several weeks before the grafting operation, but without benefit. None subsequently required amputation. In five patients sympathectomy and graft were performed simultaneously, and in three of these amputation was subsequently necessary. In eight patients sympathectomy was performed in an attempt to save the limb after the graft had failed; four of these also required amputation. Thus it was difficult to detect any striking benefit from lumbar sympathectomy in these limbs, and other surgeons have had this experience (Bloor, 1961; Taylor and Calo, 1962).

Aetiological Factors in Graft Occlusions.-It is difficult to be precise regarding the causes of graft occlusion in most of the 27 failures. However, in two cases the graft was ligated because of secondary haemorrhage following staphylococcal wound infection, and a further three grafts were of inadequate calibre, being less than the $5 \mathrm{~mm}$. recommended by Linton and Darling (1962). All the successful grafts met this requirement. The arteriograms of 54 limbs were reviewed and the run-off assessed, as suggested by Linton and Darling (1962), as excellent (popliteal and tibial vessels of normal calibre), good (minimal disease of popliteal and tibial arteries), fair (scalloping of popliteal artery and occlusion of at least one of the three main calf arteries and narrowing of the others), or poor (disease of the popliteal artery and occlusions of two or all three of the main calf arteries). Table IV summarizes the arteriograms of both failed and successful cases; it will be seen that the majority of

Table IV.-Arteriographic Classification of Popliteal-tibial Outflow in 54 TABLE IV.- Arteriographic Classification of Popliteal-tibial Out
Limbs Before Autogenous Vein Bypass Graft

\begin{tabular}{cc|c|c|c|c|c}
\hline Classification & Excellent & Good & Fair & Poor & Total \\
\hline Patent grafts.. & $\cdots$ & 0 & 5 & 18 & 9 & 32 \\
Occluded grafts & $\cdots$ & 0 & 3 & 6 & 13 & 22
\end{tabular}

failed cases had poor popliteal-tibial outflow, though nine of the still patent grafts also fell into this category. It is also evident that 46 of the 54 limbs had a "run-off" that was classified as fair or poor, so that in $85 \%$ of this group the disease was severe as judged by this assessment. A further feature relevant to seven failed cases was seen in repeated arteriograms after the grafts had occluded. In these cases the grafts had been inserted above the level of the knee-joint line, but subsequently the development of distal progressive atherosclerotic stenosis presumably resulted in slowing of flow through the graft and ultimately thrombosis. Possible aetiological factors concerned in 25 occluded grafts are listed in Table V.

TABLE V.-Aetiological Factors in Graft Occlusions of 25 Limbs

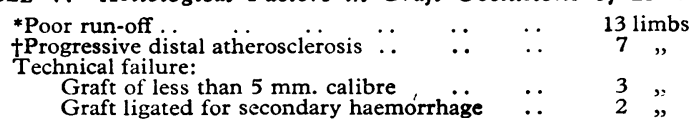

- Occlusion of two of the three main tibial arteries with irregularity of the distal popliteal artery.

$t$ Subsequent occlusion distal to the site of insertion of the graft.

\section{Associated Diseases}

Only two patients suffered from diabetes mellitus. Two had Raynaud's phenomenon and chilblains, respectively, and 11 (14\%) suffered from peptic ulcers or had undergone surgical treatment for this within the preceding 10 years.

Arterial hypertension with a diastolic pressure of $95 \mathrm{~mm}$. of mercury or greater was present in $37 \%$ of the 79 living patients. Thus $37 \%$ of the 49 sucessfully grafted living patients and $33 \%$ of the 25 failures were hypertensive.

Abnormalities of E.C.G. were present in $53 \%$ of 73 patients on whom this investigation was performed, and in 13 of these there was unequivocal evidence of myocardial infarction. On the basis of successes and failures the numbers of E.C.G. abnormalities are again almost equally divided; $51 \%$ of 45 patients with patent grafts and $52 \%$ of 23 failed patients showed abnormal E.C.G.s with seven definite myocardial infarcts in the former group and six in the latter.

\section{Mortality}

There were no operative deaths, but six patients have subsequently died. One had an occluded graft at death, but in the remaining five the graft was still patent. The causes of death and the time after operation at which death occurred are shown in Table VI. Thus the late mortality, which is usually due to the cardiac or cerebral complications of atherosclerosis, was $7.6 \%$ in this series, which is considerably lower than the $15-25 \%$ reported by others (Bloor, 1961 ; Taylor and Calo, 1962 ; Webster, 1966).

\begin{tabular}{|c|c|c|c|c|}
\hline & & & No. of Cases & Time from Graft to Death \\
\hline $\begin{array}{l}\text { Left ventricular failure } \\
\text { Cerebral haemorrhage } \\
\text { Myocardial infarction } \\
\text { Unknown .. .. }\end{array}$ & $\begin{array}{l}\ldots \\
\cdots \\
\cdots\end{array}$ & \begin{tabular}{l|l} 
\\
$\cdots$ \\
$\cdots$ \\
.
\end{tabular} & $\begin{array}{l}1 \\
1 \\
3 \\
1\end{array}$ & $\begin{array}{c}5 \text { months } \\
32 \text { '” } 18 \text { months } \\
6 \text { weeks, } 5 \text { and } 18 \text { mo } \\
26 \text { months }\end{array}$ \\
\hline
\end{tabular}

\section{Discussion}

An increasing number of reports on the results of autogenous vein bypass grafts indicate a resurgence in the popularity of this technique for the treatment of femoro-popliteal arterial occlusion. Earlier series expressed disappointment with the longterm patency, and an ill-founded fear of aneurysmal dilatation of the grafted vein in the thigh resulted in a change to other devices then becoming available (Julian et al., 1952 ; Rob, 1956). However, extensive trials of freeze-dried homografts and synthetic prostheses produced poor results which almost eliminated their usage in the thigh. Thromboendarterectomy had been compared unfavourably with autogenous vein bypass grafts (Kautzky and Brussatis, 1957 ; Szilagyi et al., 1964 ; Gutelius et al., 1965 ; De Weese et al., 1966), but commended by Cannon et al. (1958). Gryska (1960) has recommended its use for localized or segmental lesions where the vessels above and below are relatively normal; this probably agrees with the general consensus of opinion among vascular surgeons. Our personal experience with these techniques has been limited because we 
decided to give venous bypass grafts an adequate trial in the first instance, but other surgeons have reported favourably on their experiences with thromboendarterectomy supplemented by vein patching (Cockett and Maurice, 1963 ; Webster, 1966).

Our results in this present study compare less favourably in long-term patency with those of recent large surveys (Table I). However, in some series figures of long-term patency are misleading in that, though the reported length of follow-up may cover several years, the average follow-up is often less than 18 months. This would influence the results favourably. Even so, the excellent long-term patency claimed by several authors is hardly comparable with a figure of $67 \%$ at two years, as in our series. We consider the good initial patency rate at one month and at six months, respectively, tends to eliminate technical errors as an explanation. A further possible cause may lie in the initial selection of cases for operation in that less severely diseased limbs could be expected to produce better results than those with severe vascular insufficiency. In this study all the patients had severe impairment of exercise tolerance, with claudication requiring rest at 150 yards (137 metres) or less, and over $50 \%$ of them had ischaemia so gross as to render amputation imminent. It would seem that patients with poor popliteal-tibial run-off on arteriograms are liable to occlude their graft within two years owing to the progress of atherosclerotic process in the remaining tibial artery (Irvine et al., 1963). It is, however, quite surprising that many of the successful grafts are still functioning through a single major tibial artery. Thus it is often worth while to attempt a graft in a patient with severe symptoms even though the prospect of success appears slight.

In seven cases there was also evidence of progressive atherosclerotic narrowing and ultimate occlusion in the popliteal artery distal to the site of graft insertion. Singer (1963) has indicated that the proximal part of the popliteal artery is more prone to atherosclerosis, and this had led some to advocate placing the distal anastomosis below the level of the knee joint (British Medical fournal, 1966). However, as several authors have noted, and our experience again confirms, such grafts are more likely to fail than those inserted proximal to the knee joint (Table III). On balance the risk of occlusion would seem to be less when the anastomosis is proximal to the knee joint, but occasionally an adequate compromise might be to insert the graft at the level of the knee joint itself.

The value of long-term anticoagulant therapy in minimizing the risk of amputation in failed cases is again suggested by this study, as it was in our previous study on prosthetic grafts, but a fully controlled evaluation is still required (Ashton et al., 1962). Anticoagulants certainly do not seem to prevent graft occlusion. Gutelius et al. (1965) noted an association between thrombophlebitis and graft failures. Anticoagulant therapy might be expected to counteract this complication, but none of our failed cases were so affected whether on phenindione or not.

We believe that the autogenous vein bypass graft is valuable, and indeed probably the best technique at present available for the treatment of the long femoro-popliteal artery occlusion. It is not as good as recent series have suggested for advanced atherosclerotic lesions with distal disease, though gratifying limb salvage can be obtained. A drawback is the inadequate calibre of the long saphenous vein in $20-25 \%$ of limbs. In such circumstances it is necessary to resort to long thromboendarterectomy or Dacron bypass grafts. The ideal synthetic arterial substitute is still awaited, and its emergence may well herald another major advance in the surgical management of this commonplace problem.

\section{Summary}

The results of 87 autogenous vein bypass grafts for femoropopliteal arterial occlusion are reviewed and their patency over a period of 6 to 36 months is observed. One graft performed five years ago is still patent and functioning well.

Twenty-seven of the grafts have occluded at irregular intervals over a two-year period, but only six of these occurred before the patient left hospital after the graft operation.

The patency rate at one month is $93 \%$, at six months $91 \%$, at one year $73 \%$, and at two years $67 \%$.

Anticoagulant therapy appears to be beneficial in reducing the likelihood of amputation when the graft occludes, but does not appear to influence graft patency itself.

Lumbar sympathectomy does not seem to influence the outcome of arterial bypass grafts, though the numbers in this study are small.

There is a higher rate of graft failure when the distal anastomosis is sited below the level of the knee joint.

We conclude that femoro-popliteal artery reconstruction with autogenous long saphenous vein gives satisfactory results in those patients with a severe disability or where the loss of the limb is imminent. In these circumstances two grafts out of three will be patent two years later, and the limb salvage rate in cases of advanced vascular insufficiency is $73 \%$.

We thank all our colleagues who have kindly referred patients to us, and especially we thank our residents, students, and nursing staff for their enthusiastic assistance. We acknowledge with gratitude the help we have received from many colleagues in the Departments of Anaesthesia, Radiology, Biochemistry, and Clinical Pathology, and in the Blood Transfusion Service, without whose co-operation and support this work would have been impossible.

\section{REFERENCES}

Ashton, F., Slaney, G., and Rains, A. J. H. (1962). Brit. med. f., 2, 1149.

Bloor, K. (1961). Ann. roy. Coll. Surg. Engl., 28, 36.

Brit. med. F., 1966, 1, 932 .

Cannon, J. A., Barker, W. F., and Kawakami, I. G. (1958). Surgery, 43, 76.

Cockett, F. B., and Maurice, B. A. (1963). Brit. med. f., 1, 353.

De Weese, J. A., Barner, H. B., Mahoney, E. B., and Rob, C. G. (1966) Ann. Surg., 163, 205.

Edwards, W. S. (1960). Surg. Gynec. Obstet., 110, 714

Gryska, P. F. (1960). Ann. Surg., 152, 303.

Gutelius, J. R., Kreindler, S., and Luke, J. C. (1965). Surgery, 57, 28.

Irvine, W. T., Kenyon, J. R., and Stiles, P. J. (1963). Brit. med. Э., 1, 360 .

Julian, O. C., Dye, W. S., jun., Olwin, J. H., and Jordan, P. H. (1952). Ann. Surg., 136, 459 .

Kautzky, R., and Brussatis, F. (1957). Int. Abstr. Surg., 105, 79.

Kunlin, J. (1951). Rev. Chir. (Paris), 70, 206.

Linton, R. R., and Darling, R. C. (1962). Surgery, 51, 62.

Rob, C. G. (1956). Brit. med. f., 2, 1027.

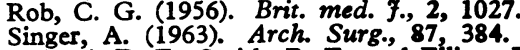

Singer, A. (1963). Arch. Surg., 87, 384. J. P. (1964). Ibld., 89, 113.

Szilagyi, D. E., Smith, R. F., and Elliott J. P. (1964), Ibld.,

Webster, J. H. H. (1966). Brit. F. Surg., 53, 607. 